\title{
Divergent Route to Gelsedine-Type Alkaloids
}

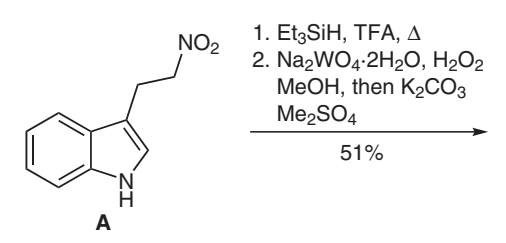<smiles></smiles>

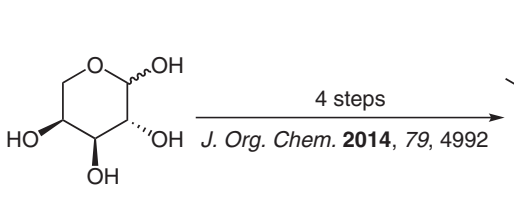

c<smiles>CC1CCC(C(C)C)C(OC2OCCCC2=O)C1</smiles>

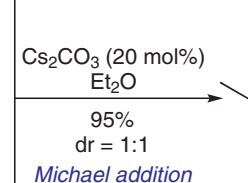
Michael addition

Synthesis of Natural

Products and

Potential Drugs

\section{Key words}

\section{Gelsemium}

alkaloids

Michael addition

aldol cyclization

pinacol

rearrangement
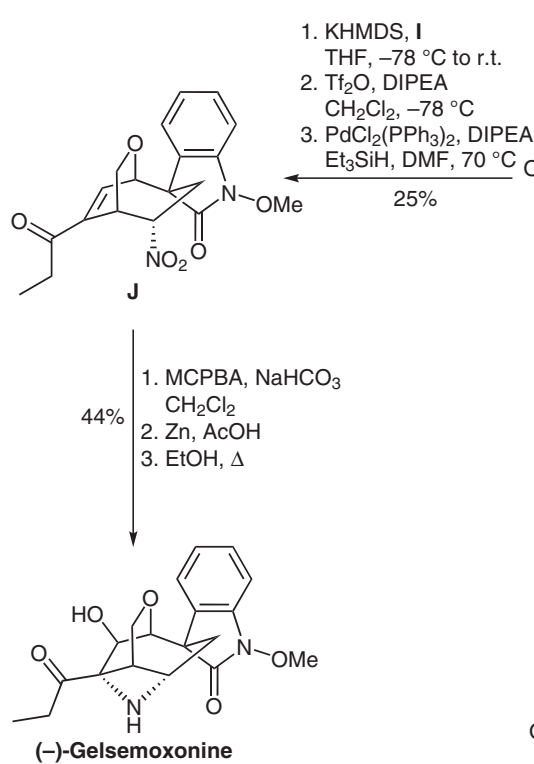

(-)-Gelsemoxonine
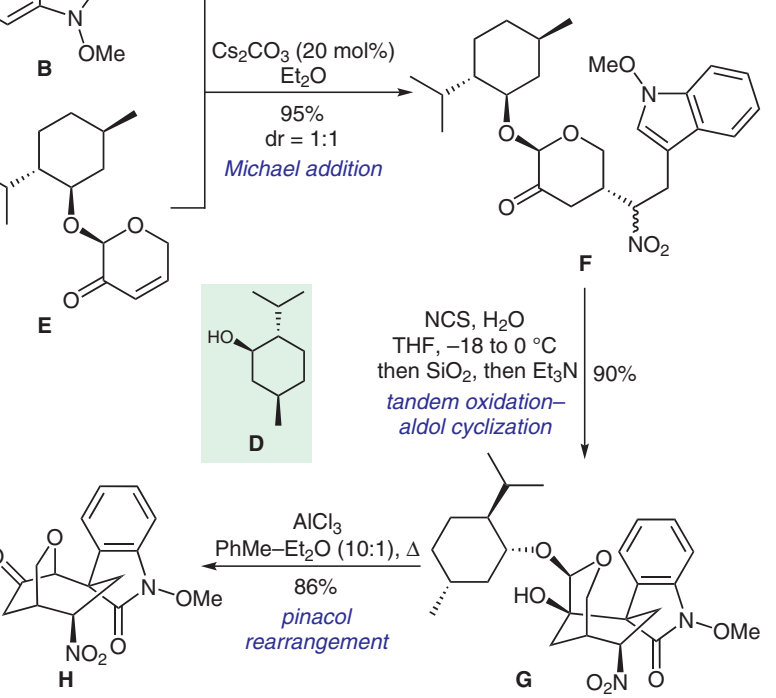

1. KHMDS, K

THF, $-78^{\circ} \mathrm{C}$ to r.t.

2. $\mathrm{Tf}_{2} \mathrm{O}$, DIPEA

$32 \% \mid \begin{array}{ll}\mathrm{CH}_{2} \mathrm{Cl}_{2},-78^{\circ} \mathrm{C} \\ \text { 3. } \mathrm{Pd}\left(\mathrm{PPh}_{3}\right)_{4}, \text { DIPEA }\end{array}$

$\mathrm{Et}_{3} \mathrm{SiH}, \mathrm{DMF}, 70^{\circ} \mathrm{C}$

4. $\mathrm{NiCl}_{2} \cdot\left(\mathrm{H}_{2} \mathrm{O}\right)_{6}, \mathrm{NaBH}_{4}, \mathrm{MeOH}$

$-10^{\circ} \mathrm{C}$, then $\mathrm{SiO}_{2}, 40^{\circ} \mathrm{C}$
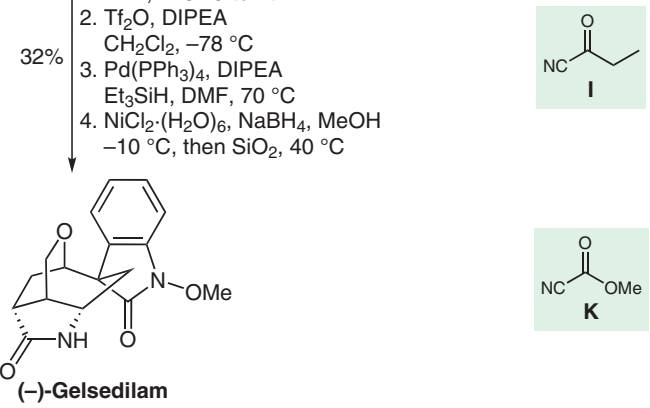

Significance: Gelsedine-type natural products have attracted considerable interest from the synthetic community owing to their interesting biological properties and complex architectures. Ma and co-workers have developed and executed an elegant synthetic route culminating in the preparation of four such alkaloids relying on an asymmetric Michael addition, tandem oxidation-aldol cyclization, and a pinacol rearrangement.
Comment: Indole derivative B and enone E underwent conjugate addition to furnish F. Oxidation and aldol cyclization resulted in the formation of key structure $\mathbf{G}$ in a single pot. Cationic rearrangement of $\mathbf{G}$ provided the oxabicyclo[3.2.2]nonane skeleton present in all targets. (-)-Gelsedilam was synthesized from $\mathbf{H}$ in four steps. (-)-Gelsemoxonine, (-)-gelsenicine, and (-)-gelsedine were accessed via ethyl ketone $\mathbf{J}$.

SYNFACTS Contributors: Erick M. Carreira, Niels Sievertsen 